\title{
Behavioral medicine solutions for overweight and obese breast cancer patients with sleep disturbances
}

\author{
D.V. Artene ${ }^{1}$, C.I. Bordea ${ }^{1,2}$ and A. Blidaru ${ }^{1,2}$ \\ ${ }^{1}$ Department of Surgical Oncology, Carol Davila Medicine University, Bucharest, Romania and ${ }^{2}$ Department of \\ Surgical Oncology, Alexandru Trestioreanu Oncology Institute, Bucharest, Romania
}

Sleep disturbances overthrow breast cancer patients' eating behavior, aggravating fat gain through hedonic hunger, insulin and leptin resistance, thus increasing recurrence and mortality risks ${ }^{(1)}$.

Seeking behavioral fat loss solutions for overweight and obese ER + breast cancer patients with sleep disturbances, we randomized 50 -of which 16 had a depression diagnosis- to follow a high protein diet based on foods naturally high in protein, calcium, omega-3, pre- and probiotics ${ }^{(2)}(\mathrm{D})$, or the diet and sleep journal $(\mathrm{D}+\mathrm{SJ})$ interventions for 8 weeks. No supplements were used. Patients were asked to keep a daily food journal where to write the time they took each meal, exactly what it contained, in what quantity, and if they were hungry or not when they ate. To improve eating behaviour, we explained the metabolic differences between eating when not hungry and eating when physically hungry, we asked patients to learn to recognize gastric hunger, to respect it by not eating when not hungry and also by eating within a maximum of 1 hour after feeling it even if they stopped feeling it ${ }^{(3)}$.

Half of the patients were asked to write a 7-day Kalionska sleep diary: the time it took them to fall asleep, number of awakenings during the night, how much they slept, how much they stayed in bed, and self-perceived sleep quality. Then they were asked to follow set sleeping and wake up hours calculated based on their SJ -using the Kalionska Institute's behavioral medicine method for increasing sleep quality- and to not sleep during the day. ${ }^{(4)} 8$ patients from the D + SJ group left the study, 5 being depressive.

We measured weight and body composition - height, total body weight (W), body fat percentage $(\% \mathrm{BF})$, skeletal muscle percentage $(\% \mathrm{SkM})$ and visceral fat percentage $(\% \mathrm{VF})$ - with a BIA scale. After the 8 week intervention patients kept the 7-day sleep log again, and we compared the self-perceived sleep quality.

D group improved body composition on all measured parameters; with no differences regarding fat loss between patients with or without depression. Non-depressive patients in D + SJ group also improved body composition on all measured parameters and they obtained an increased sleep continuity; whereas depressive patients in D + SJ group did not obtain neither statistically significant results on any measured parameters nor the improved sleep quality - maybe because of the tiring effect of the SJ intervention.

\begin{tabular}{|c|c|c|c|c|c|c|c|c|c|c|}
\hline \multirow[b]{2}{*}{ Group } & \multirow[b]{2}{*}{ Depression } & \multicolumn{3}{|c|}{ W (kg) } & \multicolumn{3}{|l|}{$\mathrm{BF} \%$} & \multicolumn{3}{|l|}{$\mathrm{VF} \%$} \\
\hline & & Mean & SD & $\mathrm{P}$ & Mean & SD & $\mathrm{P}$ & Mean & SD & $\mathrm{P}$ \\
\hline \multirow[t]{2}{*}{ Diet } & no & $2 \cdot 16$ & 2.51 & $0.001 *$ & $2 \cdot 31$ & $2 \cdot 86$ & $0.001 *$ & 0.76 & $1 \cdot 16$ & $0.003^{*}$ \\
\hline & yes & 3.62 & $3 \cdot 77$ & 0.099 & $3 \cdot 20$ & $2 \cdot 49$ & $0 \cdot 045^{*}$ & $0 \cdot 80$ & 0.44 & $0 \cdot 016^{*}$ \\
\hline \multirow[t]{2}{*}{ Diet + SJ } & no & $2 \cdot 21$ & 2.93 & $0.007 *$ & $2 \cdot 16$ & $2 \cdot 35$ & $0.002 *$ & 0.76 & 0.97 & $0.005^{*}$ \\
\hline & yes & 1.86 & 3.67 & 0.269 & 1.56 & 3.08 & 0.268 & 0.66 & 0.81 & $0 \cdot 102$ \\
\hline
\end{tabular}

Values are means for two independent measurements. Mean values were significantly different for patients with depression in D + SJ group (Student's t-test, followed

by Welch's t-test): $\mathrm{P}<0 \cdot 05$.

So, both D and D + SJ interventions improve breast cancer patients' body composition despite sleep disturbances. But D + SJ intervention improves sleep quality only in patients without depression, decreasing fat regain risk.

1. Chlebowski RT, Aiello E \& McTiernan A (2002) J Clin Oncol 20, 1128-1143.

2. Calvo MB, Figueroa A, Pulido EG et al. (2010) Int $J$ Endocrinol 2010, 1-14.

3. Ciampolini M, Lovell-Smith HD, Kenealy T et al. (2013) Int J Gen Med 6, 465-478.

4. Nordin M, Ákerstedt T \& Nordin S (2013) Sleep Biol Rhythm 11, 216-226. 